\title{
PENGARUH LINGKUNGAN KERJA DAN KOMPENSASI TERHADAP KINERJA PADA DIVISI LABORATORIUM PT. WINGS SURYA
}

\author{
M Harianto ${ }^{1}$, M Anang Firmansyah ${ }^{2}$, Rina Maretasari ${ }^{3}$ \\ Universitas Muhammadiyah Surabaya
}

\begin{abstract}
PT. Wings Surya pays attention to the work environment and compensation to improve employee performance. This study examines the influence of the work environment (X1) and compensation (X2) on employee performance (Y) in the laboratory division of PT. Wings Surya. This study aims to determine the effect of the work environment and compensation on employee performance. This study uses a descriptive quantitative approach. Data collection methods used were distributing questionnaires and recording documents. Data analysis in this study uses multiple linear regression analysis which is processed using a computer with the SPSS 20 for Windows program. Based on the results of research testing can be drawn two conclusions that Work environment (X1) and compensation (X2) affect simultaneously (simultaneously) on employee performance in the laboratory division of PT. Wings Surya (Y) because the Fcount value is 51,548> Ftable 3,172. Among the work environment (X1) and compensation (X2) the more dominant variable significantly influences the employee's performance on the laboratory division of PT. Wings Surya is Compensation (X2) because the regression coefficient is biggest that is 0,481 .. Researcher suggest to Human Resources Department PT. Wings Surya pays attention to the work environment and compensation. In order for employees of laboratory division of PT. Solar Wings can improve their performance.
\end{abstract}

Keywords : Performance, Work Environment and Compensation

Correspondence to : muhammadharianto@gmail.com, anang.firmansyah@fe.umsurabaya.ac.id, rina.maretasari@fe.um-surabaya.ac.id

\section{ABSTRAK}

PT. Wings Surya memperhatikan lingkungan kerja dan kompensasi untuk meningkatkan kinerja karyawan. Penelitian ini meneliti tentang pengaruh lingkungan kerja (X1) dan kompensasi (X2) terhadap kinerja karyawan (Y) pada divisi laboratorium PT. Wings Surya. Penelitian ini bertujuan untuk mengetahui pengaruh lingkungan kerja dan kompensasi terhadap kinerja karyawan. Penelitian ini menggunakan pendekatan kuantitatif deskriptif. Metode pengumpulan data yang digunakan adalah menyebarkan kuesioner dan mencatat dokumen-dokumen. Analisis data dalam penelitian ini menggunakan analisis regresi linier berganda yang diolah menggunakan komputer dengan program SPSS 20 for Windows. Berdasarkan hasil pengujian penelitian dapat ditarik dua kesimpulan yaitu Lingkungan kerja (X1) dan kompensasi (X2) berpengaruh secara bersama-sama (simultan) terhadap kinerja karyawan pada divisi laboratorium PT. Wings Surya (Y) karena nilai Fhitung 51,548 > Ftabel 3,172. Diantara lingkungan kerja (X1) dan kompensasi (X2) variabel yang 
lebih dominan secara signifikan pengaruhnya terhadap kinerja karyawan pada divisi laboratorium PT. Wings Surya adalah Kompensasi (X2) karena koefisien regresinya paling besar yaitu 0,481. Peneliti menyarankan kepada bagian Human Resources Departement PT. Wings Surya memperhatikan lingkungan kerja dan kompensasi. Agar karyawan divisi laboratorium PT. Wings Surya dapat meningkatkan kinerjanya.

Kata kunci $\quad$ : Kinerja, Lingkungan Kerja dan Kompensasi

Korespondensi : muhammadharianto@gmail.com, anang.firmansyah@,fe.umsurabaya.ac.id, rina.maretasari@fe.um-surabaya.ac.id

\section{PENDAHULUAN}

Sumber daya manusia masih menjadi sorotan dan tumpuhan bagi perusahaan untuk tetap dapat bertahan di era globalisasi. Sumber daya manusia mempunyai peranan yang penting dalam suatu perusahaan karena sumber daya manusia merupakan aset perusahaan yang harus dikembangkan dengan baik. Sumber daya manusia merupakan satusatunya sumber daya yang dapat menggerakkan sumber daya lainnya dalam mencapai tujuan perusahaan.

Lingkungan kerja adalah segala sesuatu yang ada disekitar para pekerja dan yang dapat memengaruhi dirinya dalam menjalankan tugas-tugas yang dibebankan (Nitisemito, 1984). Lingkungan kerja dalam suatu perusahaan sangat penting untuk diperhatikan oleh manajemen. Lingkungan kerja yang kondusif memberikan rasa aman dan memungkinkan para karyawan untuk dapat bekerja dengan maksimal.

Kompensasi adalah segala sesuatu yang diterima para karyawan sebagai balas jasa untuk kerja mereka (Handoko, 2014). Kompensasi harus dikelola secara serius dan tepat oleh perusahaan karena dapat membantu perusahaan/ organisasi dalam mencapai tujuan. Jika kompensasi tidak dikelola dengan baik, akan mengganggu jalannya usaha dan akan mengakibatkan karyawan tidak puas atas balas jasa yang diterimanya.

Kinerja karyawan merupakan hasil kerja yang dicapai seseorang dalam melaksanakan tugas sesuai tanggung jawab yang diberikan kepadanya. Mangkunegara (2015) menyatakan bahwa kinerja (prestasi kerja) adalah hasil secara kualitas dan kuantitas yang dicapai seorang karyawan dalam 
melaksanakan tugasnya sesuai dengan tanggung jawab yang diberikan kepadanya.

Perusahaan PT. Wings Surya yang bergerak dalam memproduksi aneka kebutuhan konsumen khususnya dalam bentuk deterjen harus mampu untuk bersaing dengan perusahaan lain yang hasil produksinya sejenis. Persaingan sebagai pendorong perusahaan untuk dapat mencapai tujuan yang direncanakan. Manajemen perusahaan diharapkan untuk meninjau kembali usahanya supaya dapat mengikuti perkembangan di sektor usaha ini sehingga dapat menghasilkan produk yang berkualitas dan dapat memuaskan konsumen. Manajemen perusahaan juga diharapkan dapat memperhatikan faktorfaktor yang dapat meningkatkan kinerja karyawan. Faktor-faktor tersebut diantaranya adalah faktor lingkungan kerja dan kompensasi.

Berdasarkan latar belakang dan permasalahan, peneliti tertarik mengadakan penelitian dengan judul "Pengaruh Lingkungan Kerja dan Kompensasi terhadap Kinerja Karyawan pada Divisi Laboratorium PT. Wings Surya".

\section{Landasan Teori}

\section{Lingkungan Kerja}

\section{a. Pengertian Lingkungan Kerja}

Nitisemito dalam Sunyoto (2015) menyatakan bahwa lingkungan kerja adalah segala sesuatu yang ada di sekitar para pekerja dan yang dapat memengaruhi dirinya dalam menjalankan tugas-tugas yang dibebankan, misalnya kebersihan, musik, penerangan, dan lainlain.

Dari beberapa pendapat di atas maka jelaslah bahwa yang dimaksud dengan kondisi lingkungan kerja adalah suatu kondisi atau keadaan yang ada disekitar lingkungan tempat bekerja yang dapat memengaruhi kinerja seseorang dalam melaksanakan tugas-tugasnya baik secara langsung maupun tidak langsung dan memengaruhi optimalisasi hasil yang diperoleh dan berpengaruh juga terhadap produktivitas perusahaan secara umum.

\section{b. Jenis Lingkungan Kerja:}

Sedarmayanti dalam Surjosuseno (2015) menyatakan bahwa secara garis besar, jenis lingkungan kerja terbagi menjadi dua yaitu:

1) Lingkungan Kerja Fisik

Lingkungan kerja fisik adalah semua keadaan yang berbentuk fisik yang 
terdapat di sekitar tempat kerja yang dapat memengaruhi karyawan baik secara langsung maupun tidak langsung.

2) Lingkungan Kerja Non Fisik

Lingkungan kerja non fisik adalah semua keadaan yang terjadi yang berkaitan dengan hubungan kerja, baik dengan atasan maupun hubungan sesama rekan kerja ataupun hubungan dengan bawahan.

\section{c. Faktor-faktor Lingkungan Kerja}

Setiap perusahaan tentunya mempunyai cara atau suatu faktor yang mendukung demi keberhasilan dan kemajuan perusahaan. Ada beberapa faktor yang berkaitan dengan lingkungan organisasi (Nitisemito, 1984), yaitu: hubungan kerja, tingkat kebisingan, peraturan kerja, penerangan, sirkulasi udara, dan keamanan.

\section{Kompensasi}

\section{a. Pengertian Kompensasi}

Sunyoto (2015) menyatakan bahwa salah satu cara manajemen untuk meningkatkan kepuasan kerja para karyawan adalah melalui kompensasi. Sedangkan Kasmir (2016) menyatakan bahwa kompensasi merupakan balas jasa yang diberikan perusahaan kepada karyawannya, baik bersifat keuangan maupun non keuangan.

Secara umum kompensasi merupakan sebagian kunci pemecahan bagaimana membuat anggota berbuat sesuai dengan keinginan organisasi. Sistem kompensasi ini akan membantu menciptakan kemauan diantara orangorang yang berkualitas untuk bergabung dengan organisasi dan melakukan tindakan yang diperlukan organisasi. Karyawan harus merasa bahwa dengan melakukannya, mereka akan mendapatkan kebutuhan penting yang mereka perlukan. Dimana di dalamnya termasuk interaksi sosial, status, penghargaan, pertumbuhan dan perkembangan.

\section{b. Jenis-Jenis Kompensasi}

Kasmir (2016) menyatakan bahwa secara garis besar, jenis kompensasi terbagi menjadi dua macam yaitu:

1.Kompensasi keuangan

Kompensasi keuangan merupakan kompensasi yang di berikan dalam bentuk uang baik secara periodik (mingguan, bulanan atau tahunan). Jenis kompensasi keuangan dapat berupa: gaji, upah, bonus, komisi, dan insentif. 
1. Kompensasi bukan keuangan

Kompensasi bukan keuangan merupakan kompensasi yang diberikan dalam bentuk tunjangan-tunjangan guna meningkatkan kesejahteraan karyawan baik fisik maupun batin. Jenis kompensasi bukan keuangan terdiri dari: tunjangan kesehatan, tunjangan anak/ istri, tunjangan perumahan, tunjangan kendaraan, tunjangan komunikasi, tunjangan kelangkaan, tunjangan kemahalan, tunjangan pendidikan, tunjangan liburan, tunjangan hari tua dan tunjangan hari raya.

\section{c. Tujuan Kompensasi}

Handoko dalam Sunyoto (2015) menyatakan bahwa tujuan pemberian kompensasi ada dua yaitu:

1. Bagi tenaga kerja

Dengan adanya pemberian kompensasi kepada tenaga kerja akan memperoleh keuntungan finansial dan nonfinansial antara lain:

a. Tenaga kerja mendapat upah yang lebih besar, hal ini mendorong karyawan berusaha memperoleh upah yang lebih besar guna memperbaiki hidupnya.

b. Tenaga kerja dapat terdorong mengembangkan diri masing-masing.
Dengan kompensasi akan mendorong karyawan menganalisis pekerjaannya dengan baik sehingga kecakapannya meningkatkan kepuasan.

2. Bagi perusahaan

Adapun yang menjadi tujuan pemberian kompensasi adalah meningkatkan kepuasan dan produktivitas kerja karyawan sehingga memberi motivasi kepada tenaga kerja untuk bekerja lebih bersemangat, bekerja lebih disiplin, dan bekerja lebih cepat.

\section{d. Faktor-faktor yang Memengaruhi} Kebijakan Kompensasi

Mangkunegara

menyatakan bahwa ada enam faktor yang memengaruhi kebijakan kompensasi, yaitu: faktor pemerintah, peraturan bersama antar perusahaan dengan pegawai, tandart dan biaya hidup pegawai, ukuran perbandingan upah, permintaan dan persediaan, dan kemampuan membayar

\section{Kinerja}

\section{a. Pengertian Kinerja}

Mangkunegara (2015) menyatakan bahwa kinerja berasal dari kata $J o b$ Performance dan Actual Performance (prestasi kerja atau prestasi sesungguhnya 
yang dicapai oleh seseorang). Pengertian kinerja (prestasi kerja) adalah hasil secara kualitas dan kuantitas yang dicapai seorang pegawai (karyawan) dalam melaksanakan tugasnya sesuai dengan tanggung jawab yang diberikan kepadanya. Sedangkan Kasmir (2016) menyatakan bahwa kinerja merupakan hasil kerja dan perilaku kerja seseorang dalam suatu periode, biasanya 1 tahun.

\section{b. Faktor-faktor yang Memengaruhi Kinerja}

Menurut Kasmir (2016) faktor-faktor yang memengaruhi kinerja baik hasil maupun perilaku kerja adalah sebagai berikut: Kemampuan dan keahlian, pengetahuan, rancangan kerja, kepribadian, motivasi kerja, kepemimpinan, gaya kepemimpinan, budaya organisasi, kepuasan kerja, lingkungan kerja, loyalitas, komitmen, dan displin kerja

\section{c. Faktor-faktor yang Dipengaruhi Kinerja}

Kasmir (2016) menyatakan bahwa ada beberapa faktor yang dipengaruhi kinerja baik secara langsung maupun tidak langsung sebagai berikut: kompensasi, jenis karier, dan citra karyawan laboratorium PT. Wings Surya (Y)?

\section{Hipotesis}

Berdasarkan kajian pustaka, penelitian terdahulu dan model analisis yang telah dikemukan sebelumnya maka hipotesis dalam penelitian ini sebagai berikut :

1. Lingkungan kerja $\left(X_{1}\right)$ dan kompensasi $\left(\mathrm{X}_{2}\right)$ secara simultan berpengaruh terhadap kinerja karyawan pada divisi laboratorium PT. Wings Surya (Y).

2. Lingkungan kerja $\left(\mathrm{X}_{1}\right)$ berpengaruh dominan terhadap kinerja karyawan pada divisi laboratorium PT. Wings Surya (Y).

\section{METODE PENELITIAN}

Penelitian ini akan dilaksanakan di PT. Wings Surya berlokasi di jalan raya Driyorejo km. 22,9 kecamatan Driyorejo kabupaten Gresik Jawa Timur Indonesia. Penelitian ini dilaksanakan pada divisi laboratorium PT. Wings Surya.

Dalam penelitiaan ini menggunakan pendekatan penelitian kuantitatif yaitu pendekatan penelitiaan dengan menekankan pada pengujian data.

Data yang digunakan adalah data primer yaitu data dari jawaban responden yang selanjutnya diolah dengan menggunakan analisis regresi liner berganda, analisis reliabilitas, dan 
validitas, uji asumsi klasik, analisis koefisien determinasi berganda, koefisien korelasi berganda, uji $\mathrm{t}$ dan uji $\mathrm{F}$ untuk mengetahui pengaruh variabel lingkungan kerja $\left(\mathrm{X}_{1}\right)$ dan kompensasi $\left(\mathrm{X}_{2}\right)$ terhadap kinerja karyawan (Y). Populasi dalam penelitian sebanyak 125 karyawan dan besar sampelnya sebesar 56 karyawan dengan mengunakan teknik pengambilan sampel yaitu propotionate random sampling. Data penelitian ini diperoleh langsung dari sumbernya atau responden melalui kuisoner sedangkan data sekunder adalah data yang diperoleh secara tidak langsung melalui dokumen perusahaan dan penelitian terdahulu.

\section{Analisis Data}

\section{Uji Instrumen}

\section{a. Menguji Validitas}

Uji validitas dilakukan berkenaan dengan ketepatan alat ukur terhadap konsep yang diukur sehingga benar-benar mengukur apa yang seharusnya diukur. Menurut Riduwan (2007) menjelaskan bahwa validitas adalah suatu ukuran yang menunjukan tingkat keandalan atau kesahihan suatu alat ukur. Alat ukur yang kurang valid berarti memiliki validitas rendah. Untuk menguji validitas alat ukur terlebih dahulu dicari harga korelasi antara bagian-bagian dari alat ukur secara keseluruhan dengan cara mengkorelasikan setiap butir alat ukur dengan skor total yang merupakan jumlah tiap skor butir. Untuk menghitung validitas alat ukur digunakan rumus Pearson Product Moment.

$$
\begin{aligned}
& \text { rhitung } \\
& = \\
& \frac{n\left(\sum X i Y i\right)-\left(\sum X i\right) \cdot(\Sigma Y i)}{\sqrt{\left(n \cdot \Sigma X i^{2}-(\Sigma X i)^{2}{ }^{2}\left(n \Sigma Y^{2}-(\Sigma Y i)^{2}\right)\right.}}
\end{aligned}
$$

(Riduwan (2007:109-110)

\section{Keterangan :}

$\mathrm{r}_{\text {hitung }}=$ Koefisien korelasi

$\mathrm{Xi}=$ jumlah skor item

$\mathrm{Yi}=$ jumlah skor total

$\mathrm{n}=$ Jumlah resposden

Selanjutnya dihitung dengan uji $t$ dengan rumus :

$\mathrm{t}_{\text {hitung }}=\frac{r \sqrt{n-2}}{\sqrt{1-r^{2}}} \quad,($ Riduwan (2007)

Keterangan:

$\mathrm{t}=$ Nilai thitung

$\mathrm{r} \quad=$ Koefisien korelasi hasil $\mathrm{r}_{\text {hitung }}$

$\mathrm{n} \quad=$ Jumlah responden

Kaidah keputusan : jika thitung $>t_{\text {tabel }}$ berarti valid, sebaliknya : jika $t_{\text {hitung }}<$ $\mathrm{t}_{\text {tabel }}$ berarti tidak valid

b. Menguji Reliabilitas

Uji reliabilitas dilakukan untuk mendapatkan tingkat ketepatan alat pengumpul data yang digunakan. Uji 
reliabilitas instrumen dilakukan dengan

rumus alpha Cronbach. Menurut

Riduwan (2007)

Rumus alpha sebagai berikut :

$\mathrm{r}_{11}=\left(\frac{k}{k-1}\right)\left(1-\frac{\Sigma s i}{s t}\right)$

Keterangan :

$\mathrm{r}_{11}=$ Nilai reliabilitas $\sum \mathrm{Si}=$ Jumlah varians skor tiap-tiap

item

St $\quad=$ Varians total

$\mathrm{k}=$ jumlah item

Standarisasi reliabilitas berdasarkan kaidah reliabilitas Guilfor. Berikut adalah tabel reliabilitas Guilfor :

\begin{tabular}{|l|l|}
\hline \multicolumn{1}{|c|}{ Koefisien } & \multicolumn{1}{c|}{ Kriteria } \\
\hline$<0,2$ & Tidak Reliabel \\
$0,2-0,39$ & Kurang Reliabel \\
$0,4-0,69$ & Cukup Reliabel \\
$0,7-0,89$ & Reliabel \\
$>0,9$ & Sangat Reliabel \\
\hline
\end{tabular}

Sumber : Riduwan (2007)

\section{Uji Hipotesis}

a. Uji Asumsi Klasik

Uji asumsi klasik terdiri dari normalitas, uji heteroskedastisitas. dan uji multikolonieritas.

1) Uji Normalitas

Uji normalitas digunakan untuk mengetahui apakah suatu data tersebut mengikuti sebaran normal atau tidak. Untuk mengetahui apakah data tersebut mengikuti sebaran normal dapat dilakukan dengan berbagai metode diantaranya metode kalmogorov smirnov, dengan menggunakan SPSS 20 (Ghozali, 2013). Pedoman dalam mengambil keputusan apakah suatu distribusi data mengikuti distribusi normal adalah:

a. Jika nilai signifikan (nilai probalitasnya) lebih kecil dari 5\% maka distribusinya adalah tidak normal.

b. Jika nilai signifikan (nilai probalitasnya) lebih besar dari 5\% maka distribusinya adalah normal.

2) Uji Heteroskedastisitas

Uji heteroskedastisitas bertujuan untuk menguji apakah dalam model regresi terjadi ketidaksamaan variance dari residual satu pengamatan ke pengamatan yang lain. Jika variance dari residual satu 
pengamatan ke pengamatan yang lain tetap, maka disebut homoskedastisitas dan jika berbeda disebut heteroskedastisitas. Model regresi yang baik adalah yang homoskedastisitas atau tidak tejadi heteroskedastisitas. Kebanyakan data crossection mengandung situasi heteroskedastisitas karena data ini menghimpun data yang mewakili berbagai ukuran (kecil, sedang, dan besar) (Ghozali, 2013). Mendeteksi adanya heteroskedastisitas adalah sebagai berikut:

1. Nilai probabilitas $>0,05$ berarti bebas dari heteroskedastisitas

2. Nilai probabilitas $<0,05$ berarti terkena heteroskedastisitas

3) Uji Multikolinieritas

Uji multikolinieritas digunakan untuk menunjukkan adanya hubungan linear antar varibel-variabel bebas dalam suatu model regresi. Salah satu cara yang digunakan untuk mengetahui ada tidaknya multikolinieritas yaitu dengan melihat besarnya nilai variance inflation factor (VIF). Tolerance mengukur variabilitas variabel bebas yang terpilih tidak dapat dijelaskan oleh variabel bebas lainnya. Jadi nilai tolerance yang rendah sama dengan nilai VIP tinggi (karena VIF $=1 /$ tolerance. Nilai cutoff yang umum dipakai untuk menunjukkan adanya multikolinieritas adalah nilai tolerance $\leq$ 0,10 atau sama dengan nilai $\mathrm{VIF} \geq 10$ (Ghozali, 2013).

Jadi dapat disimpulkan bahwa sebelum mengujikan regresi maka harus terlebih dahulu uji asumsi klasik yang terdiri dari uji \\ normalitas, uji heteroskedastisitas, dan uji multikolinieritas.

\section{HASIL PENELITIAN DAN DISKUSI}

\section{Pengujian Asumsi Klasik}

Pengujian asumsi klasik diperlukan untuk mengetahui apakah hasil estimasi regresi yang dilakukan benar-benar bebas.

\section{a. Normalitas}

Pengujian normalitas dengan metode Kolmogorov Smirnov:

\section{One-Sample Kolmogorov-Smirnov Test}

\begin{tabular}{|l|r|}
\hline & $\begin{array}{c}\text { Standardized } \\
\text { Residual }\end{array}$ \\
\hline $\mathrm{N}$ & 56 \\
\hline
\end{tabular}


Normal Parameters ${ }^{\mathrm{a}, \mathrm{b}}$

Most Extreme Differences

Kolmogorov-Smirnov Z

Asymp. Sig. (2-tailed)
Mean

Std. Deviation

Absolute

Positive

Negative
0E-7

,98164982

, 136

, 136

$-, 114$

1,020

a. Test distribution is Normal.

b. Calculated from data.

Dari tabel di atas menunjukkan nilai signifikansi pada residual terstandarisasi model regresi. Nilai signifikansi adalah $0,250>0,05$ sehingga data berdistribusi normal. Sehingga menunjukkan bahwa model regresi layak dipakai karena memenuhi unsur normalitas.

\section{b. Multikolinieritas}

Coefficients a

\begin{tabular}{|l|l|c|}
\hline \multirow{2}{*}{ Model } & \multicolumn{2}{|l|}{ Collinearity statistics } \\
\cline { 2 - 3 } & Tolerance & VIF \\
\hline $\mathrm{X}_{1}$ & 0 & 1,421 \\
\hline $\mathrm{X}_{2}$ & 0,704 & 1,421 \\
\hline & 0,704 & \\
\hline
\end{tabular}

Dari tabel tersebut didapatkan nilai

tolerance untuk variabel bebasnya $>0,1$ dan VIF nya $<10$. Nilai ini menunjukkan bahwa tidak terjadi multikolinieritas antar variabel bebas.

\section{c. Heteroskedastisitas}

Uji Heteroskedastisitas bertujuan menguji apakah dalam model regresi terjadi ketidak samaan variance dari residual satu pengamatan kepengamatan yang lain. Jika variance dari residual satu pengamatan ke pengamatan yang lain tetap, maka disebut Homoskedastisitas dan jika berbeda disebut Heteroskedastisitas. Model regresi yang baik adalah yang Homoskedastisitas atau tidak terjadi Heteroskedastisitas. Pengujian Heteroskedastisitas dengan metode Glejser dapat dilihat pada tabel berikut: 


\section{Coefficients $^{\mathrm{a}}$}

\begin{tabular}{|c|c|c|c|c|c|}
\hline \multirow[t]{2}{*}{ Model } & \multicolumn{2}{|c|}{ Unstandardized Coefficients } & \multirow{2}{*}{$\frac{\text { Standardized Coefficients }}{\text { Beta }}$} & \multirow[t]{2}{*}{$\mathrm{T}$} & \multirow[t]{2}{*}{ Sig. } \\
\hline & $\mathrm{B}$ & Std. Error & & & \\
\hline (Constant) & ,456 & 1,398 & & ,326 & ,745 \\
\hline Lingkungan Kerja &,- 070 & ,076 &,- 144 &,- 910 & ,367 \\
\hline Kompensasi &, 116 &, 061 & ,303 & 1,913 & .061 \\
\hline
\end{tabular}

a. Dependent Variable: ABRES

Dari tabel di atas dapat disimpulkan bahwa:

- Pada Variabel Lingkungan Kerja $\left(X_{1}\right)$ nilai signifikansi $0,367>0,05$ sehingga $X_{1}$ tidak terjadi gejala heteroskedastisitas.

- Pada Variabel Kompensasi $\left(\mathrm{X}_{2}\right)$ nilai signifikansi $0,061>0,05$ sehingga $\mathrm{X}_{2}$ tidak terjadi gejala heteroskedastisitas.

Dengan demikian dapat disimpulkan bahwa tidak terjadi heteroskedastisitas pada model regresi, sehingga model regresi layak.

\section{Analisis Regresi}

Analisa dalam penelitian ini menggunakan variabel bebas Lingkungan Kerja $\left(\mathrm{X}_{1}\right)$ dan Kompensasi $\left(\mathrm{X}_{2}\right)$, sedangkan variabel terikat (Y) adalah Kinerja Karyawan. Untuk mengetahui seberapa besar pengaruh variabel bebas $\mathrm{X}_{1}$ dan $\mathrm{X}_{2}$ terhadap variabel terikat $(\mathrm{Y})$, maka dapat dihitung dengan menggunakan teknik analisa regresi linier berganda. Berdasarkan pada hasil perhitungan dari model regresi linier berganda, diperoleh hasil persamaan regresi yang dapat dilihat dalam tabel dibawah ini: 
Balance Vol. XV No. 2 | Juli 2018

\section{Coefficients $^{\mathrm{a}}$}

\begin{tabular}{|c|c|c|c|c|c|c|c|c|}
\hline \multirow{2}{*}{\multicolumn{2}{|c|}{ Model }} & \multicolumn{2}{|c|}{ Unstandardized Coefficients } & \multirow{2}{*}{\begin{tabular}{|l}
$\begin{array}{l}\text { Standardized } \\
\text { Coefficients }\end{array}$ \\
Beta
\end{tabular}} & \multirow[t]{2}{*}{$\mathrm{T}$} & \multirow[t]{2}{*}{ Sig. } & \multirow{2}{*}{\begin{tabular}{|l} 
Collinearity \\
Statistics
\end{tabular}} & \multirow[b]{2}{*}{ VIF } \\
\hline & & B & Std. Error & & & & & \\
\hline \multirow{3}{*}{1} & (Constant) & 1,817 & 1,955 & &, 930 &, 357 & & \\
\hline & $\begin{array}{l}\text { Lingkungan } \\
\text { Kerja }\end{array}$ &, 426 &, 107 &, 381 & 3,993 &, 000 & ,704 & 1,421 \\
\hline & Kompensasi &, 481 &, 085 &, 540 & 5,660 &, 000 &, 704 & 1,421 \\
\hline
\end{tabular}

a. Dependent Variable: Kinerja Karyawan

Sumber: Data Primer Diolah

\section{Analisa Koefisien Korelasi (R) dan Koefisien Determinasi $\left(\mathbf{R}^{2}\right)$}

Model Summary

\begin{tabular}{|c|c|c|c|c|}
\hline $\begin{array}{c}\text { Mod } \\
\text { el }\end{array}$ & $\mathrm{R}$ & $\begin{array}{c}\mathrm{R} \\
\text { Square }\end{array}$ & $\begin{array}{c}\text { Adjusted R } \\
\text { Square }\end{array}$ & $\begin{array}{c}\text { Std. Error } \\
\text { of the } \\
\text { Estimate }\end{array}$ \\
\hline 1 &, $813^{\mathrm{a}}$ &, 660 &, 648 & 2,60334 \\
\hline
\end{tabular}

a. Predictors: (Constant), Kompensasi, Lingkungan Kerja

b. Dependent Variable: Kinerja Karyawan
Berdasarkan hasil output SPSS diatas dapat diketahui bahwa nilai koefisien korelasi adalah 0,813. Hal ini memberikan arti bahwa hubungan antara variable Lingkungan Kerja $\left(\mathrm{X}_{1}\right)$ dan Kompensasi $\left(\mathrm{X}_{2}\right)$ terhadap kinerja karyawan (Y) sangat kuat dan bernilai positif, artinya semakin tinggi nilai jawaban responden pada variabel Lingkungan Kerja (X1) dan Kompensasi (X2) maka semakin tinggi pula Kinerja Karyawan(Y). Demikian pula sebaliknya semakin rendah nilai jawaban responden pada variabel Lingkungan Kerja $\left(\mathrm{X}_{1}\right)$ dan Kompensasi $\left(\mathrm{X}_{2}\right)$ maka semakin rendah pula Kinerja Karyawan (Y).

$$
\text { Sedangkan nilai koefisien }
$$
determinasi 0,660 atau $66,0 \%$. Hal ini memberikan arti bahwa Lingkungan Kerja $\left(\mathrm{X}_{1}\right)$ dan Kompensasi $\left(\mathrm{X}_{2}\right)$ memengaruhi Kinerja Karyawan (Y) 
sebesar $66,0 \%$ dan sisanya $34,0 \%$ dipengaruhi oleh variable lain diluar penelitian.

\section{Pengujian Hipotesis}

\section{a. Uji F (Simultan)}

Dalam penelitian ini desertakan pengujian serentak (uji F) untuk mengetahui apakah variabel bebas yaitu Lingkungan Kerja $\left(\mathrm{X}_{1}\right)$ dan Kompensasi $\left(\mathrm{X}_{2}\right)$ secara serentak atau bersama sama berpengaruh terhadap Kinerja Karyawan (Y). Untuk itu dalam penelitian ini desertakan uji $\mathrm{F}$ seperti yang terlihat dalam tabelberikut ini:

ANOVA ${ }^{\mathrm{a}}$

\begin{tabular}{|l|l|l|l|l|l|}
\hline Model & $\begin{array}{l}\text { Sum of } \\
\text { Squares }\end{array}$ & df & $\begin{array}{l}\text { Mean } \\
\text { Square }\end{array}$ & F & Sig. \\
\hline $\begin{array}{l}\text { Regress } \\
\text { ion }\end{array}$ & 698,727 & 2 & 349,364 & 51,548 &, 000 \\
\hline $\begin{array}{l}\text { Residua } \\
1 \\
\text { Total }\end{array}$ & 359,202 & 53 & 6,777 & & \\
\hline
\end{tabular}

a. Dependent Variable: Kinerja Karyawan

b. Predictors: (Constant), Kompensasi, Lingkungan Kerja

\section{Sumber : Data Primer Diolah}

Karena nilai signifikasi $0,000<0,05$ dan nilai $F_{\text {hitung }}(51,548)>F_{\text {tabel }}(3,172)$ maka H0 ditolak dan $\mathrm{H} 1$ diterima. Hal ini menunjukkan bahwa Lingkungan Kerja $\left(\mathrm{X}_{1}\right)$ dan Kompensasi $\left(\mathrm{X}_{2}\right)$ secara serentak atau bersama sama berpengaruh terhadap Kinerja Karyawan (Y).

\section{b. Uji t (Parsial)}

Dalam penelitian ini juga dicantumkan uji parsial (uji t) untuk mengetahui apakah variabel Lingkungan Kerja $\left(X_{1}\right)$ dan Kompensasi $\left(\mathrm{X}_{2}\right)$ secara parsial atau sendiri-sendiri berpengaruh terhadap Kinerja Karyawan (Y). Berikut ini terdapat tabel untuk merekap pengaruh variabel bebas $\mathrm{X}_{1}$ dan $\mathrm{X}_{2}$ terhadap variabel (Y) terikat. Lihat tabel ini:

Coefficients $^{\mathrm{a}}$

Standardized Coefficients
Collinearity Statistics 


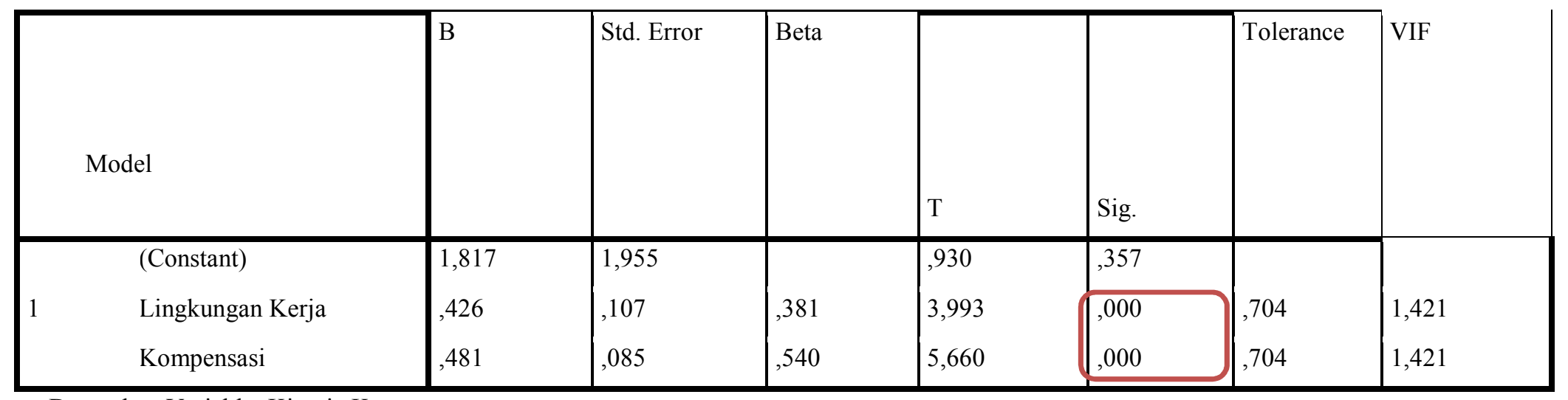

a. Dependent Variable: Kinerja Karyawan

Sumber :Data Primer diolah

Karena nilai signifikan $0,000<0,05$ dan nilai $t_{\text {hitung }}(3,993)>t_{\text {tabel }}(2,006)$ maka H0 ditolak dan $\mathrm{H} 1$ diterima. Hal ini menunjukkan bahwa secara parsial variabel Lingkungan Kerja $\left(\mathrm{X}_{1}\right)$ berpengaruh terhadap Kinerja Karyawan (Y).

Karena nilai signifikan $0,000<0,05$ dan nilai $\mathrm{t}_{\text {hitung }}(5,660)>\mathrm{t}_{\text {tabel }}(2,006)$ maka H0 ditolak dan $\mathrm{H} 1$ diterima. Hal ini menunjukkan bahwa secara parsial variabel Kompensasi $\left(\mathrm{X}_{2}\right)$ berpengaruh terhadap Kinerja Karyawan (Y).

Berdasarkan nilai koefisien regresi dan uji t yang dilakukan pada kedua variable dependen maka dapat disimpulkan bahwa variabel yang dominan berpengaruh terhadap Kinerja Karyawan (Y) adalah variabel Kompenasi $\left(\mathrm{X}_{2}\right)$. Hal ini terbukti bahwa variable Kompensasi $\left(\mathrm{X}_{2}\right)$ memiliki koefisien regresi yang paling besar yaitu 0,481 .

\section{DISKUSI}

Penelitian mengenai pengaruh lingkungan kerja dan kompensasi terhadap kinerja karyawan pada divisi laboratorium PT. Wings Surya, dapat dilihat pembahasan sebagai berikut:

\section{Pengaruh Lingkungan Kerja} terhadap Kinerja Karyawan

Lingkungan kerja merupakan bagian komponen yang sangat penting ketika karyawan melakukan aktifitas bekerja (Sunyoto, 2015). Kasmir (2016) menyatakan bahwa lingkungan kerja merupakan suasana atau kondisi di sekitar lokasi tempat bekerja. Jika lingkungan kerja dapat membuat suasana nyaman dan memberikan ketenangan maka akan membuat suasana kerja 
menjadi kondusif, sehingga dapat meningkatkan hasil kerja seseorang menjadi lebih baik.

Hasil penelitian ini menunjukkan bahwa lingkungan kerja secara parsial berpengaruh terhadap kinerja karyawan pada divisi laboratorium PT. Wings Surya. Dibuktikan dengan melakukan uji hipotesis (Uji t) dimana hasil perhitungan nilai $t_{\text {hitung }}$ untuk variabel lingkungan kerja adalah 3,993 lebih besar dari nilai $t_{\text {tabel }}$ yaitu 2,006 dengan signifikan 0,000 $<0,05$ artinya variabel lingkungan kerja $\left(\mathrm{X}_{1}\right)$ berpengaruh terhadap variabel kinerja karyawan. Bahwa semakin baik lingkungan kerja dalam perusahaan maka akan meningkatkan kinerja karyawan dalam pencapaian tujuan perusahaan.

Hal ini sejalan dengan penelitian dari Surjosuseno (2015) hasil penelitian menunjukkan ada hubungan signifikan lingkungan kerja terhadap kinerja karyawan, dimana lingkungan kerja memainkan peran penting dalam menciptakan lingkungan manusia yang dapat dikembangkan dan dibina. Perlunya memahami lingkungan kerja dalam perusahaan sebagai suatu hal yang bermakna positif, maka tidak diragukan bahwa karyawan akan melakukan tindakan- tindakan yang lebih produktif.
Hasil penelitian ini juga sejalan dengan Prahiawan dan Simbolan (2014) yang menunjukkan bahwa lingkungan kerja berpengaruh signifikan terhadap kinerja karyawan. Lingkungan kerja yang kondusif akan membantu perusahaan memberikan kepastian bagi seluruh sumber daya manusia untuk berkembang bersama perusahaan dan bersama-sama meningkatkan kegiatan usaha dalam menghadapi persaingan, walaupun tingkat pertumbuhan dari masing-masing individu bervariasi. Sebaliknya lingkungan kerja yang tidak kondusif tidak akan mampu memberikan dorongan kepada karyawan untuk memilki keinginan maju dan berkembang bersama perusahaan.

\section{Pengaruh Kompensasi terhadap Kinerja Karyawan}

Kompensasi adalah segala sesuatu yang diterima para karyawan sebagai balas jasa untuk kerja mereka (Handoko, 2014). Kompensasi merupakan balas jasa yang diberikan perusahaan kepada karyawannya. Karyawan yang memiliki kinerja yang baik tentu akan memperoleh balas jasa seperti kenaikan gaji atau tunjangan lainnya (Kasmir, 2016). 
Hasil penelitian ini menunjukkan bahwa kompensasi secara parsial dan yang paling dominan berpengaruh terhadap kinerja karyawan pada divisi laboratorium PT. Wings Surya. Hasil penelitian ini berbeda dengan hipotesis pada bab II yang menyatakan bahwa variabel lingkungan kerja lebih dominan berpengaruh terhadap kinerja karyawan. Hal ini dikarenakan variabel Kompensasi $\left(\mathrm{X}_{2}\right)$ memiliki koefisien regresi yang paling besar yaitu 0,481 dibandingkan dengan variabel Lingkungan Kerja yang koefisien regresinya 0,426 . Dibuktikan dengan melakukan uji hipotesis (Uji t) dimana hasil perhitungan nilai thitung untuk variabel kompensasi adalah 5,660 lebih besar dari nilai $t_{\text {tabel }}$ yaitu 2,006 dengan signifikan $0,000<0,05$ artinya kompensasi $\left(\mathrm{X}_{2}\right)$ berpengaruh terhadap variabel kinerja karyawan. Bahwa semakin baik kompensasi di dalam sebuah perusahaan maka akan meningkatkan kinerja karyawan.

Hal ini sejalan dengan penelitian Wijaya dan Andreani (2015) hasil penelitian menunjukkan bahwa kompensasi berpengaruh terhadap kinerja karyawan. Penelitian yang dilakukan oleh Dhermawan, Sudibya, dan Utama (2012) juga menunjukkan bahwa kompensasi berpengaruh terhadap kinerja karyawan. Kompensasi merupakan faktor penting untuk meningkatkan kinerja karyawan. Dengan demikian perusahaan perlu mengelola kompensasi dengan baik, supaya kinerja karyawan tetap terjaga dan mampu mendorong karyawan untuk selalu melakukan hal yang terbaik dan menghindari frustasi kerja yang berakibat pada penurunan kinerja karyawan.

\section{Pengaruh lingkungan kerja dan kompensasi terhadap Kinerja Karyawan}

Dari hasil penjabaran diatas dapat disimpulkan bahwa ada pengaruh lingkungan kerja dan kompensasi bersama-sama (simultan) memberikan pengaruh signifikan terhadap kinerja karyawan pada divisi laboratorium PT. Wings Surya. Hasil signifikan diperoleh dari uji $\mathrm{F}$ (simultan) dengan nilai sebesar $F_{\text {hitung }} 51,548$ lebih besar dari $\mathrm{F}_{\text {tabel }}$ 3,172 dengan signifikan $0,000<0,05$ hal ini menunjukkan secara simultan lingkungan kerja dan kompensasi berpengaruh terhadap kinerja karyawan. Lingkungan kerja dan kompensasi dapat meningkatkan kualitas kerja yang baik bagi karyawan dan perusahaan. Untuk itu diperlukan sebuah pengelolaan perusahaan yang baik agar semua tujuan 
perusahaan dapat tercapai dengan memuaskan, serta kesejahteraan dari karyawan yang bekerja juga ikut terjamin dan mengalami peningkatan dalam kehidupan sehingga akan meningkatkan kinerja karyawan.

\section{G. SIMPULAN}

Berdasarkan hasil pengujian penelitian dapat ditarik dua kesimpulan untuk menjawab rumusan masalah sebagai berikut:

1. Lingkungan kerja $\left(\mathrm{X}_{1}\right)$ dan kompensasi $\left(\mathrm{X}_{2}\right)$ berpengaruh secara bersama-sama (simultan) terhadap kinerja karyawan pada divisi laboratorium PT. Wings Surya (Y).

2. Diantara lingkungan kerja $\left(\mathrm{X}_{1}\right)$ dan kompensasi $\left(\mathrm{X}_{2}\right)$ variabel yang lebih dominan secara signifikan pengaruhnya terhadap kinerja karyawan pada divisi laboratorium PT. Wings Surya adalah Kompensasi $\left(\mathrm{X}_{2}\right)$.

\section{H. SARAN}

Dari hasil penelitian maka diberikan masukan dan saran sebagai berikut:
1. Sebagaimana diketahui bahwa lingkungan kerja dan kompensasi merupakan faktor yang berpengaruh terhadap kinerja, maka diharapkan pada divisi laboratorium PT. Wings Surya memperhatikan faktor- faktor tersebut untuk lebih meningkatkan kinerja.

2. Agar dapat meningkatkan kinerja secara optimal, hendaknya terus melakukan perbaikan dan pengawasan terhadap karyawan, untuk menjaga dan meningkatkan kualitas sumber daya manusia pada divisi laboratorium PT. Wings Surya.

3. Kepada para peneliti selanjutnya disarankan agar lebih memperdalam unit analisisnya, baik variabel maupun indikator penelitian, sehingga dapat lebih mempertajam hasil yang sudah penulis peroleh di dalam penelitian ini.

\section{DAFTAR PUSTAKA}

Arianto, D. A. (2013). Pengaruh Kedisiplinan, Lingkungan Kerja dan Budaya Kerja terhadap Kinerja Tenaga Pengajar. Jurnal Economia, 9(2), 191-200. 
Arikunto, S. (2010). Prosedur Penelitian Suatu Pendekatan Praktik. Jakarta: Rineka Cipta.

Dhermawan, A. A., Sudibya, I. G., \& Utama, I. W. (2012). Pengaruh Motivasi, Lingkungan Kerja, Kompetensi, dan Kompensasi terhadap Kepuasan Kerja dan Kinerja Pegawai di Lingkungan Kantor Dinas Pekerjaan Umum Provinsi Bali. Jurnal Manajemen, Strategi Bisnis, dan Kewirausahaan, 6(2), 173-184.

Fatihudin, D. (2012). Metode Penelitian untuk Ilmu Ekonomi, Manajemen dan Akuntansi dari Teori ke Praktek. Surabaya: PPs UMSurabaya.

Ghozali, I. (2013). Aplikasi analisis multibariate dengan program SPSS. Semarang: Badan Penerbit Universitas Diponegoro.

Handaru, A. W. (2013). Pengaruh Lingkungan Kerja, Kompensasi dan Komitmen Organisasi terhadap Kepuasan Kerja Karyawan di RS "X”. Jurnal Riset Manajemen Sains Indonesia (JRMSI), 4(1), 116-135.
Handoko, T. H. (2014). Manajemen Personalia \& Sumber Daya Manusia. Yogyakarta: BPFE.

Hasibuan, M. S. (2003). Manajemen Sumber Daya Manusia. Jakarta: Bumi Aksara.

htpp://id.m.wikipedia.org/wiki/Wings_(pe rusahaan)?_e_pi_=7\%2CPAGE_ ID10\%2C1315714556. (2016, Juli 15). Retrieved Agustus 12, 2016 Kasmir. (2016). Manajemen Sumber Daya Manusia. Jakarta: Raja Grafindo Persada.

Kusuma, N. (2014). Analisis Pengaruh Lingkungan Kerja dan Kompensasi terhadap Kinerja Pegawai pada PT. Sun Motor Jebres Surakarta. Naskah Publikasi.

Mangkunegara, A. P. (2015). Manajemen Sumber Daya Manusia Perusahaan. Bandung: Rosda.

Muhammad, S. R., Adolfina, \& Lumintang, G. (2016). Pengaruh Lingkungan Kerja, Kompensasi dan Beban Kerja terhadap Kinerja Karyawan pada Dinas Pendapatan Daerah Kota Manado. Journal EMBA, 4(1), 045-055. 
Nitisemito, A. S. (1984). Manajemen

Persoalia. Jakarta: Ghalia Indonesia.

Riduwan. (2007). Pengantar Statistika untuk Penelitian: Pendidikan Sosial, Ekonomi, Komunikasi. Bandung: CV. Alfabeta.

Riduwan. (2009). Metode \& Teknik Penyusunan Proposal Penelitian. Bandung: CV. Alfabeta.

Salbiyah, S., \& Mahardhika, B. W. (2017). Pengaruh Motivasi Kerja Terhadap Kinerja Tenaga Kependidikan Universitas Muhammadiyah Surabaya Tahun 2016. Balance, 14(02).

Simbolan, N., \& Prahiawan, W. (2014). Pengaruh Motivasi Intrinsik dan Lingkungan Kerja terhadap Kinerja Karyawan pada PT Intimas Lestari Nusantara. Jurnal Ekonomi, 5(1), 35-41.

Sugiyono. ( 2015). Metode Pnelitian Kuantitatif, kualitatif, dan $R \& D$. Bandung: CS Alfabeta.
Sunyoto, D. (2015). Penelitian Sumber Daya Manusia. Yogyakarta: Caps.

Surjosuseno, D. (2015). Pengaruh Lingkungan Kerja dan Motivasi Kerja terhadap Kinerja Karyawan pada Bagian Produksi UD Pabrik Ada Plastic. AGORA, 3(2), 175179.

Taufiq, M., \& Hidayat, Z. (2012).

Pengaruh Lingkungan Kerja dan

Disiplin Kerja serta Motivasi Kerja terhadap Kinerja Karyawan Perusahaan Daerah Air Minum (PDAM) Kabupaten Lumajang. Jurnal WIGA, 2(1), 79-97.

Usman, H., \& Akbar, R. S. (2003).

Pengantar Statistika. Jakarta:

Bumi Aksara.

Wijaya, T., \& Andreani, F. (2015).

Pengaruh Motivasi dan Kompensasi terhadap Kinerja Karyawan pada PT Sinar Jaya Abadi Bersama. AGORA, 3(2), 37-41. 